\title{
Dune dynamics and roughness under gradually varying flood waves, comparing flume and field observations
}

\author{
J. J. Warmink \\ Twente Water Centre, University of Twente, Enschede, the Netherlands \\ Correspondence to: J. J. Warmink (j.j.warmink@utwente.nl)
}

Received: 14 October 2013 - Revised: 28 May 2014 - Accepted: 1 July 2014 - Published: 7 August 2014

\begin{abstract}
Accurate forecasts of bed forms and their roughness during a flood wave are essential for flood management. Bed forms remain dynamic even under steady discharge and are subject to a continuous process of creations and destructions of individual bed forms. Dune evolution during the rising limb of a flood wave is quite well understood and can be modeled. However, dune evolution during the falling limb remains poorly understood. The objective of this paper is to explain the bed form evolution and roughness during the receding limb of fast flood waves. Therefore, bed profiles of two flume experiments were analyzed in detail and individual dune creations and destructions were classified.

The results showed that for fast flood waves in subcritical water flow: (1) dune length grows during both rising and falling limb due to amalgamation of bed forms, (2) dune length has a longer adaptation time than dune height, resulting in short, high dunes during the peak discharge, and (3) this hysteresis difference between dune height and length results in a larger roughness than predicted by equilibrium bed form dimension equations, which may result in a larger roughness of the main channel during floods than expected.
\end{abstract}

\section{Introduction}

Accurate and fast computer models are required to predict daily water level forecasts for operational flood management. River bed forms act as roughness to the flow, thereby influencing the water levels. Rivers dunes are the dominant bed forms in many rivers. The height is in the order of $10-30 \%$ of the water depth and their length in the order of 10 times their heights. Under flood conditions the bed is highly dynamic; dunes grow and decay as a result of the changing flow condi- tions. Therefore, it is essential to predict the evolution of bed forms to assess their influence on the hydraulic roughness.

Several successful attempts were made to model bed form evolution and associated roughness using detailed numerical modeling (e.g. Giri and Shimizu, 2006; Nabi et al., 2013). However, these models require long computational times and are therefore not applicable for operational flood management. Paarlberg et al. $(2009,2010)$ developed a processbased model for bed form evolution that requires limited computational effort. This model accounts for flow separation and is able to accurately predict bed form development towards equilibrium conditions and during the rising limb of a flood wave (Paarlberg et al., 2010). However, bed form dynamics especially during the falling limb of a flood wave remain poorly understood. My analysis presented here has the goal of shedding light on this phase of the dune evolution.

Bed form dimensions during the falling limb of a flood wave are often modeled using a time-lag approach (e.g. Coleman et al., 2005; Martin and Jerolmack, 2013). This approach essentially consists of adding a reduction factor to the dune height or length at time $t_{i}$, compared to a predicted equilibrium value at $t_{i}$. The equilibrium height and length are determined by an equilibrium predictor such as Van Rijn (1984). The reduction factor is based on the difference between the bed form dimension at $t_{i}$, the equilibrium value at $t_{i}$ and an empirical growth factor (e.g. Coleman et al., 2005). However, during the falling limb of a flood wave this approach yields unsatisfactory results for the dune length prediction, especially for fast flood waves. Observations show that dune length starts to decrease after the flood wave has passed and the discharge has returned to its initial value (see e.g. Figs. 3a, b and 5 in Martin and Jerolmack, 2013).

The objective of this paper is to explain the bed form evolution and associated roughness during the falling limb of a 


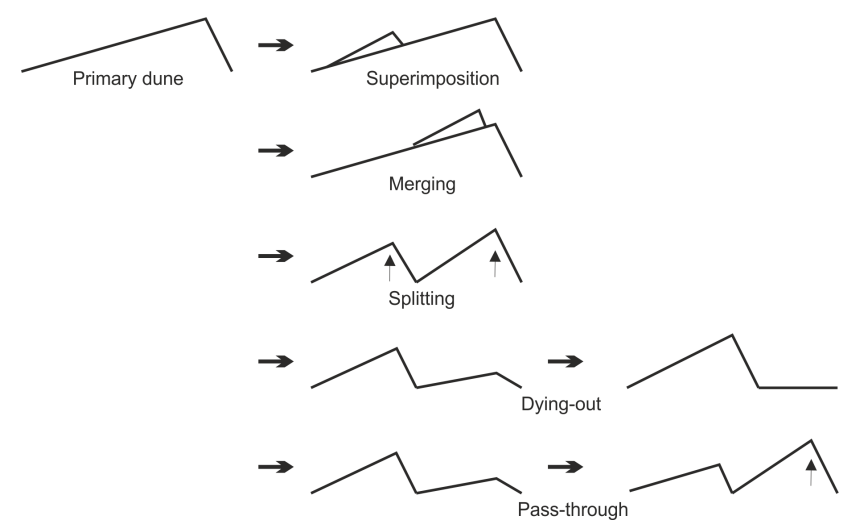

Figure 1. Illustration of the five dune creation and destruction mechanisms based on the classifications of Gabel (1993) and Martin and Jerolmack (2013).

flood wave. I reanalyzed the bed profiles of two flood waves in a flume and compared the results to field data of the river Rhine. I tracked the evolution of individual dunes and present a hypothesis for dune length evolution during the falling limb of fast flood waves. Finally, the implications for bed form roughness during such flood waves are discussed.

\section{Classification of dune interactions}

Observations in flumes and in the field have shown that dunes of different lengths and amplitude co-exist (Carling et al., 2000; Warmink et al., 2012). Carling et al. (2000) distinguished three scales of bed forms in the river Rhine: ripples, small dunes (length $<5 \mathrm{~m}$ ) and large dunes (length $>10 \mathrm{~m}$ ) and show that the latter two strongly interact. Bed forms remain dynamic even under steady discharge and are subject to a continuous process of splitting and merging. Jerolmack and Mohrig (2005) showed that individual bed forms become unrecognizable after migrating several wavelengths, because they are continuously created and destroyed.

Gabel (1993) defined four mechanisms for the creation and destruction of bed forms: (1) spontaneous creation, (2) merging, (3) splitting and (4) dying-out. With spontaneous creations Gabel (1993) refers to the appearing of superimposed bed forms, which are caused by turbulent coherent structures that develop on the stoss side of larger bed forms (e.g. Best, 2005). In addition to these four mechanisms, Martin and Jerolmack (2013) defined another mechanisms, which they refer to as pass-through, where mass is transferred from the leading to the trailing bed form. I adopted these five mechanisms (Fig. 1) to classify the interactions between individual dunes.

Essentially, merging, splitting, dying-out and pass-through are all consequences of the development of a superimposed bed form (spontaneous creation) on top of a primary dune. These superimposed bed forms may affect the primary dune in different ways. Firstly, superimposed bed form can migrate over the primary bed form, only contributing to sediment transport (Reesink and Bridge, 2009). Alternatively, the superimposed bed forms can grow thereby reducing their migration rate (because larger bed forms migrate slower than smaller bed forms) and they start to erode the underlying dune, which might lead to splitting (Warmink et al., 2014). In case of less erosion the flow separation zone of the superimposed bed form can merge with the underlying dune (Best et al., 2013) or stall on the stoss side and trap the sediment in its flow separation zone leading to dying-out of the underlying primary dune. Another possibility is that near the point of amalgamation, the superimposed bed form starts to erode the primary dune. But before the primary dune is completely eroded or dies-out, the (now small) eroded dune migrates downstream. Because it is now small, its migration rate is larger than the (now large) superimposed bed form and it can migrate out of its influence (the pass-through interaction).

\section{Observations from flume and field data}

Many flume experiments are available that show bed form evolution under different discharge conditions. However, most of these measurements were carried out for a steady discharge or for discharge steps. Wijbenga and Van Nes (1986a) carried out two experiments for a fast and a slow flood wave in the flume: experiment T43 with a flood wave duration of $T_{\text {wave }}=3.5 \mathrm{~h}$ (scaled to observed flood waves in the Dutch river Rhine) and experiment T44 with a flood wave duration of $T_{\text {wave }}=7 \mathrm{~h}$. For both experiments, the discharge ranged between 0.03 and $0.15 \mathrm{~m}^{3} \mathrm{~s}^{-1}$ resulting in water depths, $h$, ranging between 0.15 and $0.47 \mathrm{~m}$ (see Fig. 2a, b). The width of the flume was $0.5 \mathrm{~m}$ and the measuring section was $30 \mathrm{~m}$ long. Bed material consisted of uniform sand $\left(D_{50}=0.78 \mathrm{~mm}\right)$. Wijbenga and Van Nes $(1986 \mathrm{a})$ repeated both test conditions 9 times and measured the bed profiles and associated flow characteristics.

I reanalyzed the bed profiles from their experiments and determined the individual dune characteristics using the zero-crossing method of Van der Mark et al. (2008). The dimensions of the individual dunes were averaged over the length the flume and over the 9 tests to yield a representative dune height and length during the flood waves (Fig. 2c, d). I computed the roughness based on the measured flow velocity, water depth and water surface slope (Fig. 2e). Figures 2c, $\mathrm{d}$ show the individual dune dimensions for both flood waves, normalized for water depth.

Figure $3 \mathrm{a}, \mathrm{b}$ show the discharge, averaged dune heights, $\Delta[\mathrm{m}]$ and lengths, $\Lambda[\mathrm{m}]$ for both experiments. The dune heights shows a small time-lag compared to the discharge $(Q)$, while the time-lag for the dune length is significantly larger. This observation is in agreement with the observations of Martin and Jerolmack (2013). Figure 3e show the hysteresis curves for both T43 and T44 for dune length 

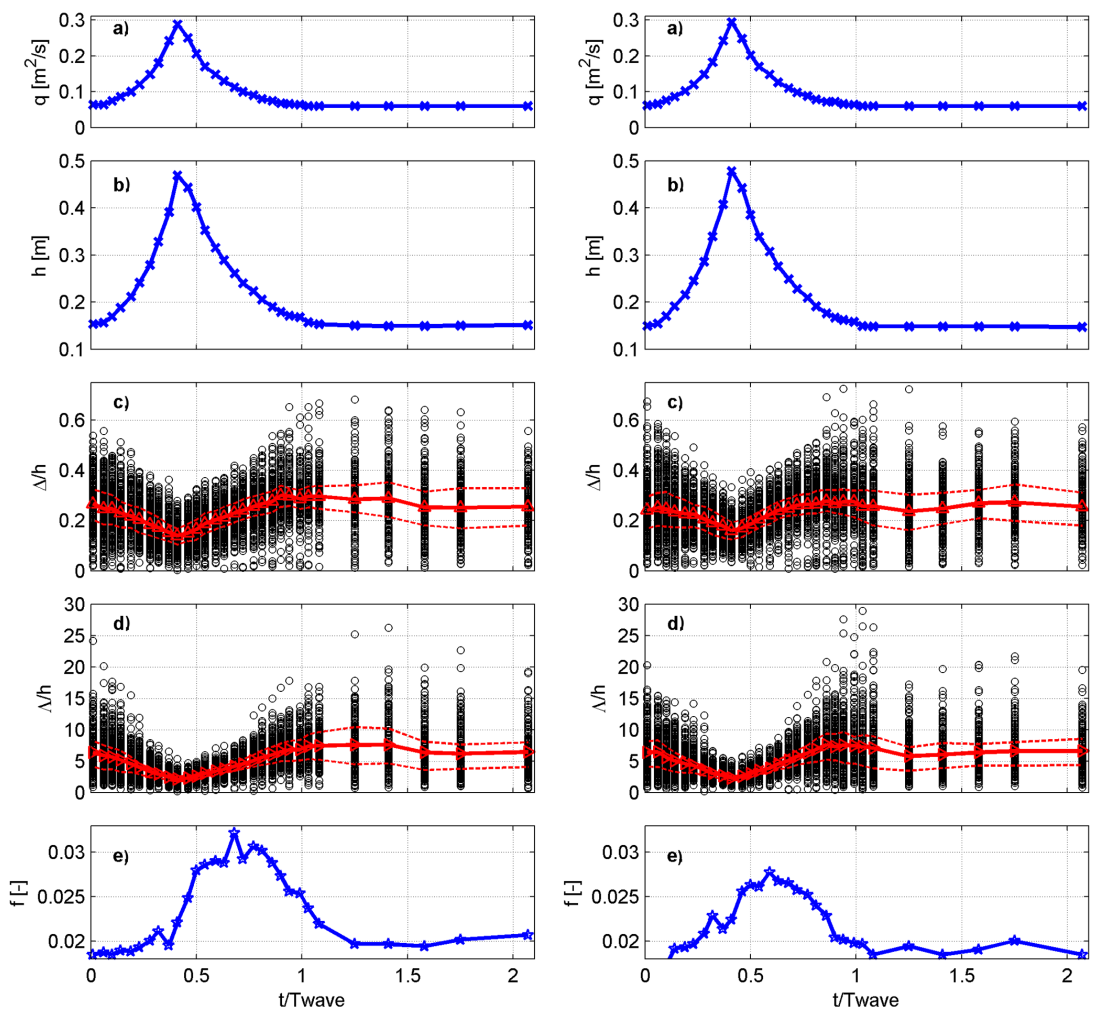

Figure 2. Timeseries of the $T_{\text {wave }}=3.5 \mathrm{~h} \mathrm{~T} 43$ (left) and $T_{\text {wave }}=7 \mathrm{~h}$ T44 (right) discharge waves of Wijbenga and Van Nes (1986a), with (a) specific discharge, (b) water depth, (c) normalized dune height of individual dunes (dots), average and 25 and $75 \%$ confidence intervals (red lines), (d) dune length and (e) total roughness, $f$.
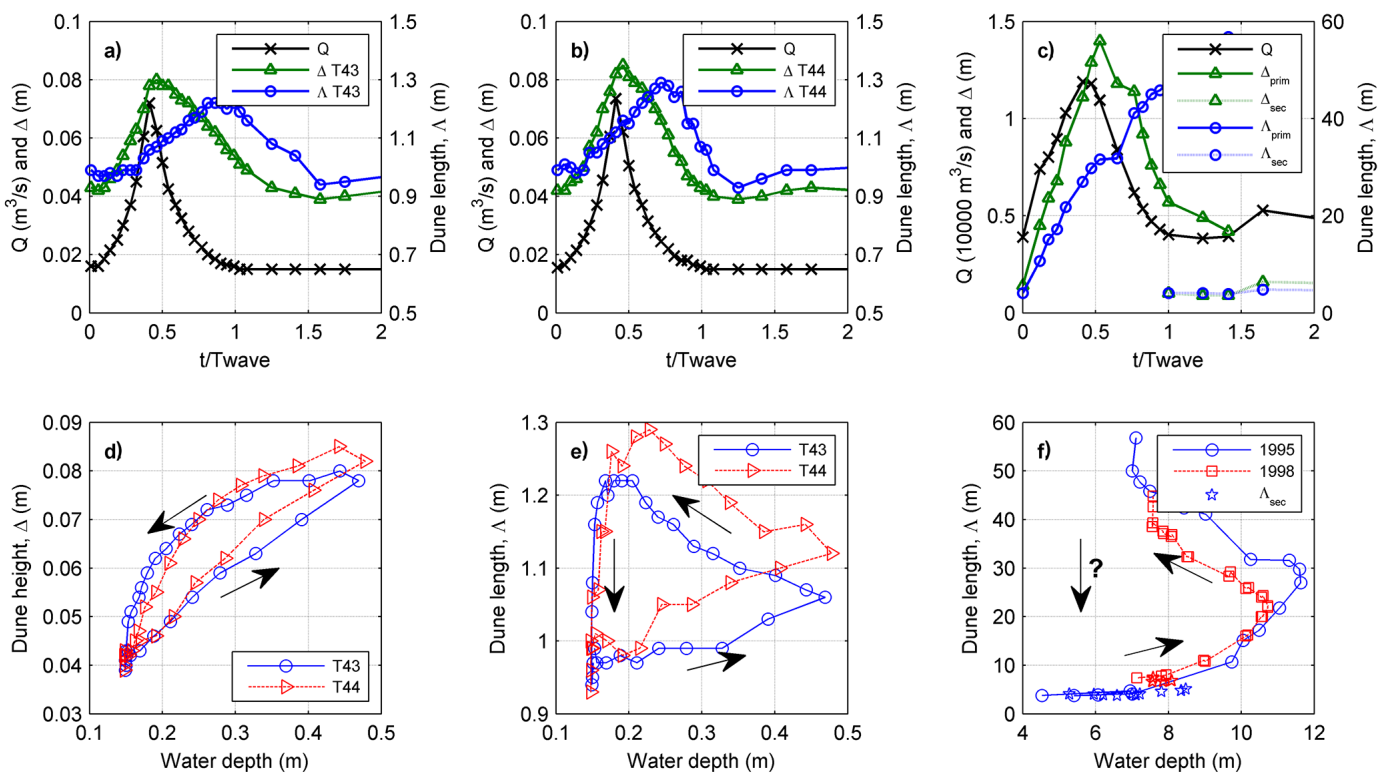

Figure 3. Averaged dune heights and lengths in the flume (a: T43, $T_{\mathrm{wave}}=3.5 \mathrm{~h}$ and (b): $\left.\mathrm{T} 44, T_{\mathrm{wave}}=7 \mathrm{~h}\right)$ and the field (c: $1995 \mathrm{flood}$ wave, $T_{\text {wave }}=17$ days). $(\mathbf{d})$ and (e) show the hysteresis curves of dune length for the two flood waves (T43 and T44) in the flume and two flood waves in the field (in 1995 and 1998). The flume data are computed from the bed profiles of Wijbenga and Van Nes (1986a) and field data are from Wilbers and Ten Brinke (2003). 

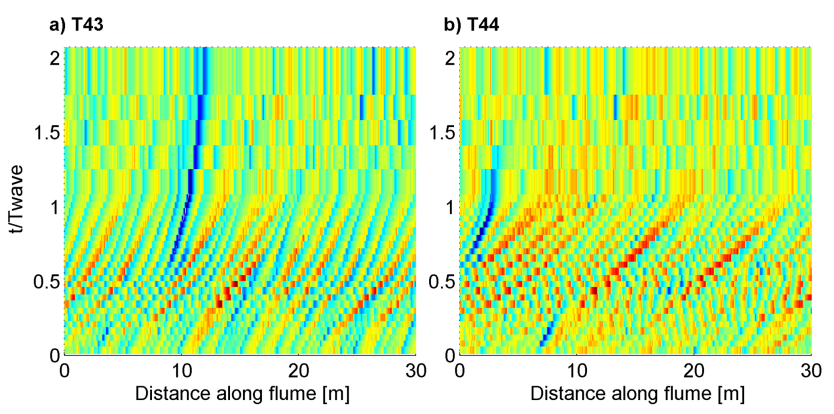

Figure 4. Color map plots of bed elevation for the fast (a: $\left.T_{\text {wave }}=3.5 \mathrm{~h}\right)$ and slow $\left(\mathbf{b}: T_{\text {wave }}=7 \mathrm{~h}\right.$ ) flood waves based on the bed profiles from test 5 of Wijbenga and Van Nes (1986a). Bed elevations range from $-5 \mathrm{~cm}$ (blue) to $5 \mathrm{~cm}$ (red).

revealing that hysteresis was stronger for the fast (T43) flood wave (also stated by Martin and Jerolmack, 2013). Figure 3a shows that dune length grows continuously during the flood wave and starts to decrease after the discharge is back to its initial value. This is also visible in Fig. 5 in Martin and Jerolmack (2013), however they do not explicitly mention it. The color map in Fig. 4a shows that the dune migration rate generally decreases after the peak of the fast flood wave (at $t / T_{\text {wave }} \approx 0.5$ ) and that the dune crests slowly decrease in height. For the fast flood wave the dune length starts to decrease at $t / \mathrm{T}_{\text {wave }} \approx 1$, while for the slow flood wave the hysteresis is less pronounced and the dune length starts to decrease at $t / T_{\text {wave }} \approx 0.8$ (Fig. 3b). Note that $T_{\text {wave }}$ for T44 is twice as large as for T43, so the migration rates, $m$, are similar $\left(m_{T 43}=1.9 \mathrm{~m} \mathrm{~h}^{-1}\right.$ and $\left.m_{T 44}=2.1 \mathrm{~m} \mathrm{~h}^{-1}\right)$. Figure $2 \mathrm{~d}$ shows that before and after the flood wave (i.e. under constant discharge) the normalized average dune length lies around the theoretical value of $7.3 \cdot h$ (Van Rijn, 1984). Dune length during the flood wave becomes smaller than $7.3 \cdot h$ and does not scale with water depth, due to the hysteresis effect.

Figure $3 \mathrm{c}$ shows the dune evolution in the field during the 1995 flood wave in the river Rhine with a $T_{\text {wave }}$ of 17 days (Wilbers and Ten Brinke, 2003). In addition to the primary dune height and length ( $\Delta_{\text {prim }}$ and $\Lambda_{\text {prim }}$ ) also the height and length of the superimposed bed forms $\left(\Delta_{\mathrm{sec}}\right.$ and $\left.\Lambda_{\mathrm{sec}}\right)$ were recorded. The primary dunes grow in height with the discharge and the height shows a time-lag of 2.1 days. After the flood wave has passed $\left(t / T_{\text {wave }}=1\right)$ superimposed bed forms appear with dimensions similar to the primary dunes prior to the flood wave. Figure $3 \mathrm{f}$ shows the hysteresis curves of the dune length of the 1995 and the 1998 flood waves in the river Rhine. These figures show that also in the field during the whole flood wave, dune length only grows and no decrease of the (primary) bed form length is observed.

During the rising limb the variation in both dune height and length strongly decreases (Fig. 2c, d). The probability densities of the dune dimensions (Fig. 5) also show that the dune shape is more regular around the peak than before and after the flood wave. This is caused by the amalgamation of
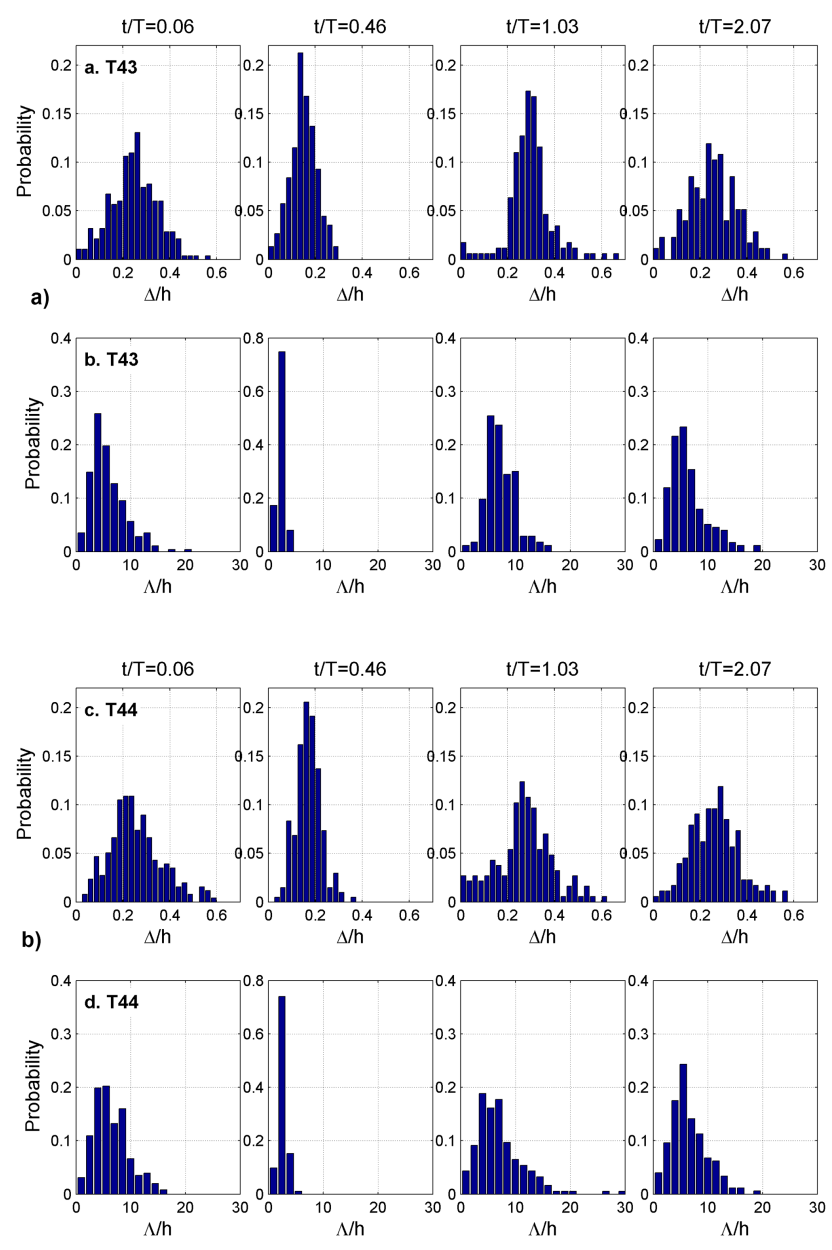

Figure 5. Probability distributions of normalized dune heights (a, c) and lengths (b, d) for the fast and slow discharge waves at three times during the steep flood wave (start: $t / T_{\text {wave }}=0.06$, peak: $t / T=0.46$, and end: $t / T_{\text {wave }}=1.03$ ) and at the end of the experiment $\left(t / T_{\text {wave }}=2.07\right)$. Number of individual dunes between $\approx 280$ $\left(t / T_{\text {wave }}=0.46\right)$ and $\approx 170\left(t / T_{\text {wave }}=2.07\right)$;

bed forms under the influence of the stronger flow and larger bed shear stress. Figures $2 \mathrm{c}, \mathrm{d}$ and $5 \mathrm{~b}, \mathrm{~d}$ also shows that long after the flood waves $\left(t / T_{\text {wave }}=2.07\right)$, there are slightly more very long dunes than before the start of the flood waves $\left(t / T_{\text {wave }}=0.06\right)$. These dunes have lengths of 10-20 times the water depth, which is much larger than the theoretical value of 7.3 (Van Rijn, 1984), so these bed forms are likely not in equilibrium.

\section{Individual dune tracking and transition classification}

Figure 6 shows the detailed bed profiles of one of the 9 tests of T43 measured by Wijbenga and Van Nes (1986a). The vertical axis shows the normalized time for $T_{\text {wave }}=3.5 \mathrm{~h}$. The right panel shows the normalized discharge, $Q$, averaged dune height, $\Delta$, and dune length, $\Lambda$, (all scaled between 


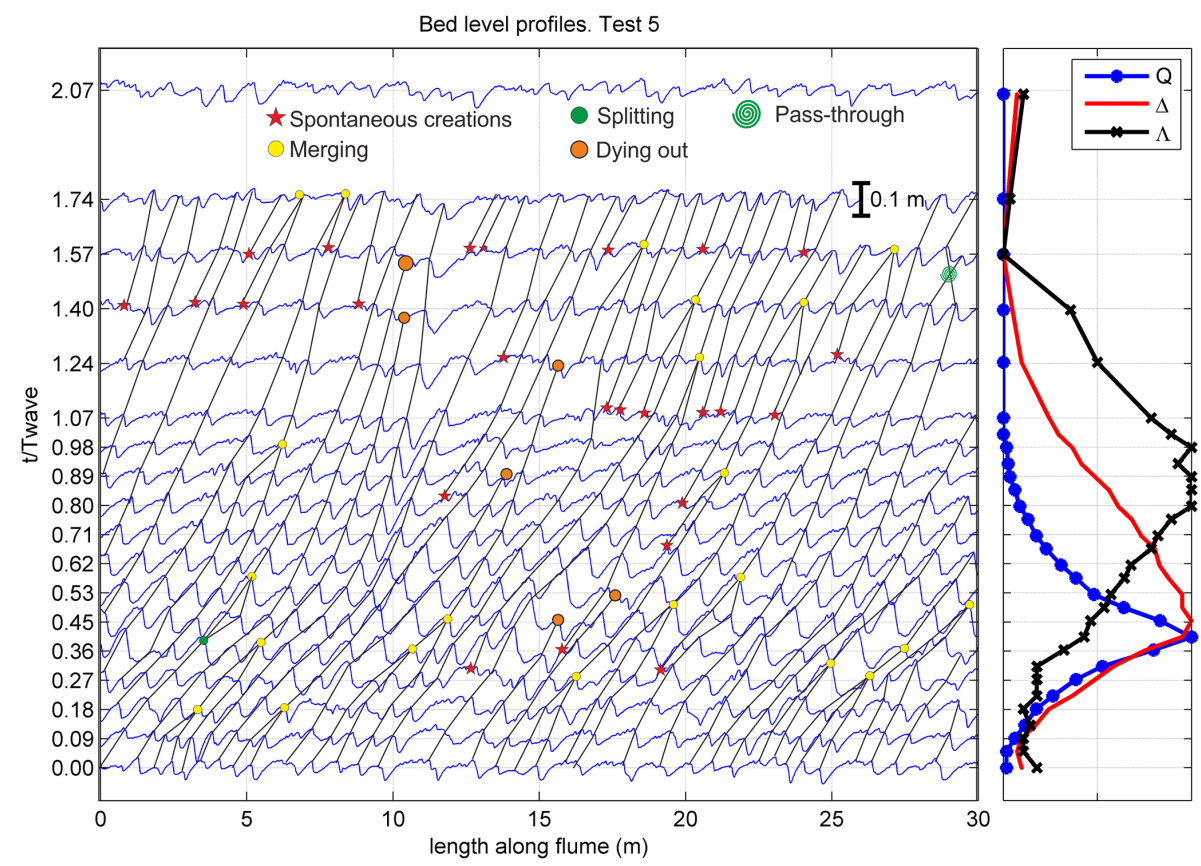

Figure 6. Bed profiles from flume experiment T43 (test 5) of Wijbenga and Van Nes (1986a). Right panel shows the discharge (Q), dune height $(\Delta)$ and length $(\Lambda)$ in time, normalized between 0 and 1 (vertical axis). The crests of individual dunes are connected with lines and dune interactions are classified as creations, merging, splitting, dying-out or pass-through.

0-1). The left panel shows the corresponding bed profiles during the flood wave. Superimposed on this figure, I drew lines connecting the crests of the individual dunes. Individual dunes were visually identified by having a steep lee side and a distinct brink point (thereby assuming flow separation). The identified dunes matched the dunes identified by the dune tracking software. After connecting the crests, I classified the points where a new dune was created or destroyed using the classification presented in Sect. 2. I repeated this procedure for all 9 tests of experiment T43 carried out by Wijbenga and Van Nes (1986a).

Initially, at $t / T_{\mathrm{wave}}=0$, the bed consists of small bed forms. During the initial stages of increasing discharge, some superimposed bed forms appear and simultaneously other dunes are dying-out. At this stage, the profiles are dominated by merging of dunes leading to longer (and higher) dunes. At $t / T_{\text {wave }} \approx 0.5$ (peak discharge), the bed pattern consists of regular high, short dunes indicated by the stable parallel lines in Fig. 6. The number of creations and destructions is small compared to the initial rising stage.

At the initial stages of falling discharge $\left(t / T_{\text {wave }}\right.$ between 0.53 and $\approx 1$ ) the dunes become slightly longer, but dune length is relatively stable. However, the dune height observations (Fig. 3a, b) show that the average dune height is decreasing. After $t / T_{\text {wave }} \approx 1$, many superimposed bed forms start to appear simultaneously on top of the primary dunes. The dunes becomes more irregular and individual dunes become more difficult to distinguish.

\section{Towards an explanation for decaying dune length}

I reanalyzed the data of Wijbenga and Van Nes (1986a) and found the following. During the falling limb of the flood wave the dunes maintain their regular shape for a relatively long period and only show a slow decay in height. The observations show that for fast flood waves dunes adapt faster to the flow during increasing discharge than during decreasing discharge. This observation can be explained by the amount of flow strength (shear stress) that is available for dune deformation during the rising limb. Large dunes require a larger flow strength to be deformed than small dunes, because more sediment needs to be transported. During increasing discharge the flow strength is in-phase with the size of the bed forms. Initially, the flow strength is small (low discharge, low flow velocities) and bed forms are also small, so bed forms can easily be deformed. During the rising limb, the flow strength increases faster than the bed forms (due to timelag) so the dunes are deformed, because the flow strength is "ahead" of the bed form dimensions. During falling discharge the opposite occurs: the flow strength decreases faster than the bed form size, so a relatively low flow strength is available to deform the large bed forms. Therefore, the dunes only show little deformation during the falling limb of the flood wave.

During the falling limb of the fast flood wave, the dune length remains almost constant. So, at the end of the flood wave $\left(t / T_{\text {wave }} \approx 1\right)$ relatively large bed forms exist that are not in equilibrium with the flow and superimposed bed forms 
appear. The flow strength during the first part of the falling limb is too large for superimposed bed forms to be formed. This is also shown in the field data (Fig. 3b), where superimposed bed forms are only observed after the flood wave ( $t / T_{\text {wave }} \approx=0.89$ ). An important question is whether or not flow separation exists behind these large bed forms that are not in equilibrium with the flow, which has large implications for the roughness. Best (2005) suggests that large bed forms with low lee-side angles are subject to intermittent flow separation, thereby significantly reducing the roughness.

After $t / T_{\text {wave }}=1$, the discharge remains constant and superimposed bed forms appear on top of the large primary dunes in both flume and field data. These superimposed bed forms migrate and thereby slowly fill the troughs of the primary dunes. Martin and Jerolmack (2013) also stated that trough-filling is responsible for the decay of the primary dunes that developed during the flood wave, which is also visible in our data (Fig. 6). However, they do not conclude that that dune length grows continuously during the flood wave.

The explanation I present here of dune length decay is only valid for fast flood waves. To determine if a flood wave is fast or slow, adaptation times can be computed using for example Coleman et al. (2005). If the adaptation time is larger than the duration of the flood wave, the flood wave is fast and dunes continue to grow throughout the falling limb of the flood wave. After the flood wave, trough filling is the main driver for dune decay.

\section{Implications for roughness}

Bed form roughness is caused by energy losses due to the flow separation zone (Van Rijn, 1984). If dunes are higher, their flow separation zone is larger, so their roughness is larger. If dune length is larger, there are less dunes per meter, so roughness decreases for longer length. Figures $2 \mathrm{e}$ show that the maximum roughness is larger for the fast than for the slow flood wave. Also, the roughness remains longer above the initial value of $f \approx 0.02$. This can be explained by the difference between the adaptation times for the fast and the slow flood wave. In the previous Sect. 1 showed that dune length adapts slower than dune height for both flood waves. Therefore, the difference in time-lag between dune heights is smaller than the difference in time-lag between dune length. Meaning that dune heights are more comparable between the flood waves than dune lengths. This has a large effect on the roughness, because for the fast flood wave, the dune length increases relatively slow, while the dune height increases fast. This leads to high, but short dunes, which are also visible in the profiles in Fig. 6 at $t / T \approx 0.5$ and in the histograms in Fig. 5. The same phenomenon is visible for the slow flood wave, but has a much smaller effect, because the time-lag for dune length is relatively smaller.
Consequently, for fast flood waves with a large hysteresis effect, the bed form roughness may become larger than expected based on equilibrium dune dimension predictors, because these do not account for hysteresis. This has large implications for water levels in rivers where roughness is dominated by bed forms and fast flood waves occur. For example, Martin and Jerolmack (2013) showed that hysteresis is substantial in the river Rhine (see also Fig. 3c), so bed form roughness at the peak of the discharge wave may be underestimated by traditional methods based on equilibrium conditions.

\section{Conclusions}

In this paper I reanalyzed flume and field experiments to explain the dune evolution during the falling limb of a fast flood wave in sub-critical water flows and its implication for the roughness. I conclude that:

- Dune length grows throughout the flood wave due to amalgamation, both during the rising and falling limb of the flood wave in case of fast flood waves. Dune length decay starts after the flood wave has passed by means of trough-filling by superimposed bed forms.

- Dune height and length show significantly different time-lags, resulting in stronger hysteresis in dune length than in dune height.

- The hysteresis difference between dune height and length results in larger roughness values at the peak of the flood wave than expected assuming equilibrium predictions. So, roughness is larger for fast than for slow flood waves.

I showed that predicting the correct time-lag between dune height and dune length might be important for accurate roughness predictions. Therefore, including dune dynamics in operational water management can improve the accuracy of water level predictions.

Acknowledgements. This study was carried out as part of the project "BedFormFlood", supported by the Technology Foundation STW, the applied science division of NWO and the technology program of the Ministry of Economic Affairs.

\section{References}

Best, J.: The fluid dynamics of river dunes, a review and some future research directions, J. Geophys. Res., 110, F04S02, doi:10.1029/2004JF000218, 2005.

Best, J., Blois, G., Barros, J., and Christensen, K.: The dynamics of bedform amalgamation: new insights from a very thin flume, edited by: Van Lancker, V. and Garlan, T., Proc. of the 4rd workshop on Marine Sandwave and River Dune Dynamics (MARID IV), 15-17 April 2013, Bruges, Belgium, 29-34, 2013. 
Carling, Gölz, Orr, and Radecki-Pawlik: The morphodynamics of fluvial sand dunes in the River Rhine, near Mainz, Germany. I. Sedimentology and morphology, Sedimentology, 47, 227-252, 2000.

Coleman, S. E., Zhang, M. H., and Clunie, T. M.: Sediment-wave development in subcritical water flow, J. Hydr. Eng., 131, 106$111,2005$.

Gabel, S. L.: Geometry and kinematics of dunes during steady and unsteady flows in the Calamus River, Nebraska, USA, Sedimentology, 40, 237-269, 1993.

Giri, S. and Shimizu, Y.: Numerical computation of sand dune migration with free surface flow, Water Resour. Res., 42, W10422, doi:10.1029/2005WR004588, 2006.

Jerolmack, D. J. and Mohrig, D.: A unified model for subaqueous bed form dynamics, Water Resour. Res., 41, 1-10, 2005.

Martin, R. L. and Jerolmack, D. J.: Origin of hysteresis in bed form response to unsteady flows, Water Resour. Res., 49, 1314-1333, 2013.

Nabi, M., de Vriend, H. J., Mosselman, E., Sloff, C. J., and Shimizu, Y.: Detailed simulation of morphodynamics: 3. ripples and dunes, Water Resour. Res., 49, 5930-5943, 2013.

Paarlberg, A. J., Dohmen-Janssen, C. M., Hulscher, S. J. M. H., and Termes, P.: Modeling river dune evolution using a parameterization of flow separation, J. Geophys. Res., 114, F01014, doi:10.1029/2007JF000910, 2009.

Paarlberg, A. J., Dohmen-Janssen, C. M., Hulscher, S. J. M. H., Termes, P., and Schielen, R. M. J.: Modelling the effect of timedependent river dune evolution on bed roughness and stage, Earth Surf. Proc. Landf., 35, 1854-1866, 2010.
Reesink, A. J. and Bridge, J.: Influence of bedform superimposition and flow unsteadiness on the formation of cross strata in dunes and unit bars. Part 2, further experiments, Sediment. Geol., 222, 274-300, 2009.

Van Rijn, L. C.: Sediment transport, part III: bed forms and alluvial roughness, J. Hydr. Eng., 110, 1733-1754, 1984.

Van der Mark, C. F., Blom, A. and Hulscher, S. J. M. H.: Quantification of variability in bedform geometry, J. Geophys. Res., 113, F03020, doi:10.1029/2007JF000940, 2008.

Warmink, J. J., Schielen, R. M. J., and Dohmen-Janssen, C. M.: Bed form evolution under varying discharges, flume versus field., in: Murillo (Ed.) Proc. of the International Conference on Fluvial Hydraulics, River Flow 2012, Costa Rica, 2012.

Warmink, J. J., Dohmen-Janssen, C. M., Lansink, J., Naqshband, S., Van Duin, O. J. M., Paarlberg, A. J., Termes, P., and Hulscher, S. J. M. H.: Understanding river dune splitting through flume experiments and analysis of a dune evolution model, Earth Surf. Proc. Landf., 39, 1208-1220, doi:10.1002/esp.3529, 2014.

Wijbenga, J. H. A. and Van Nes, A. R.: Flow resistance and bedform dimensions for varying flow conditions; results of flume experiments with flume width $1.50 \mathrm{~m}$ and $1.125 \mathrm{~m}$, TOW rivers R 567 - XXIII/M 1314 part XI, WL|Delft Hydraulics, Delft, The Netherlands, 1986a.

Wilbers, A. W. E. and Ten Brinke, W. B. M.: The response of subaqueous dunes to floods in sand and gravel bed reaches of the Dutch Rhine, Sedimentology, 50, 1013-1034, 2003. 